\title{
Patologías prevalentes en pacientes de etnia china
}

\author{
D. LY PEN \\ Médico de Familia. Centro de Salud "Castillo de Uclés". Área 4. Madrid
}

\section{RESUMEN}

En primer lugar, se repasan las principales características y costumbres de las personas de etnia china que viven en la actualidad en España.

Posteriormente, se hace una revisión bibliográfica práctica de las patologías más frecuentes en personas de etnia china. Asimismo, se adjunta un vocabulario médico básico y algunos números de teléfono que nos pueden resultar útiles en caso de que la comunicación con pacientes chinos sea dificultosa.

Palabras clave: Etnia china. Patologías prevalentes. Características culturales.
Prevalent diseases of Chinese people in Spain

Key words: Chinese ethnology. Prevalent diseases. Cultural characteristics.

\section{INTRODUCCIÓN}

Es de todos conocido que a nuestro país están llegando muchas personas de los más diversos países, con sus peculiares costumbres, creencias, alimentación y patologías. Por ello es deseable que el médico de Atención Primaria conozca lo máximo posible de las diferentes etnias, para saber interpretar su sintomatología y poder mejorar en definitiva la asistencia médica que prestamos a nuestros pacientes.

Aunque las personas de raza china no sean las que más frecuenten nuestra consulta, sí pueden ser con las que más dificultades tengamos para comunicarnos, probablemente por la radical diferencia de cultura e idioma. Hay muy pocas publicaciones acerca de las peculiaridades de la etnia china ${ }^{1,2}, \mathrm{y}$ ninguna de ellas en España. En las siguientes líneas intentaremos orientar sobre los aspectos más importantes de la idiosincrasia de los inmigrantes chinos en nuestro medio, así como repasar sucintamente sus patologías más frecuentes.

\section{PROCEDENCIA DE LOS INMIGRANTES CHINOS}

El $92 \%$ de la población china es han. El $8 \%$ restante queda repartido entre etnias zhuang, uygur, yi, miao, mongoles, tibetanos, etc. La inmensa mayoría de los chinos en España son de etnia han.

Aproximadamente desde 1950 a 1970, los inmigrantes chinos en España eran muy escasos en número, pues apenas eran unos pocos centenares en toda España. Procedían sobre todo de Hong-Kong, Macao y Taiwan (también conocida como Formosa). 
En la últimas dos décadas, la mayoría de los inmigrantes chinos que han llegado a España proceden de la República Popular China, sobre todo de la provincia de Zhejiang.

\section{IDIOMA}

Los inmigrantes procedentes de Hong-Kong, Macao y del Sur de China, hablarán con seguridad el cantonés, y la mayoría de ellos comprenderá también el mandarín. Los procedentes del resto de la República Popular de China, hablan mandarín y muchos de ellos también su dialecto local.

Los procedentes de Taiwan hablan mandarín y muchos también el minnan (taiwanés).

Un aspecto interesante a destacar es el que a pesar de que en China existen doce grandes dialectos (con pronunciaciones tan diferentes que impiden el entendimiento entre ellos), el lenguaje escrito es el mismo en todos ellos, y por tanto entendido por la totalidad de los chinos alfabetizados.

\section{ESTRUCTURA SOCIAL Y VIDA FAMILIAR}

Probablemente más que cualquier otra etnia, los chinos tienden a retener su estructura sociofamiliar y sus actividades culturales con relativo poco contacto con las actividades sociales locales o nacionales del país al que emigran. La familia es un aspecto primordial de su vida social. Para los jóvenes, el respeto por los padres, personas de mayor edad y "figuras de autoridad" tales como profesores y maestros, forma una parte muy importante de su actitud ante la vida. Tampoco es menos cierto que estos roles también están en crisis, en sintonía con la sociedad en la que están trasplantados ${ }^{1}$.

\section{RELIGIÓN}

China es un país oficialmente aconfesional. De hecho la mayoría de los chinos procedentes de la República Popular de China no profesan religión alguna, posiblemente por influencia del régimen comunista, pues aunque la religión era tolerada, no se fomentaba.

El confucionismo, más que una religión, es una doctrina, un catálogo de normas de funcionamiento social, que durante siglos ha sido la base de toda la vida en China ${ }^{3}$. Tales normas no han sido fáciles de erradicar en una generación de régimen comunista.

\section{PROFESIONES}

Hasta hace dos décadas, casi el $90 \%$ de los inmigrantes chinos trabajaban en el ramo de la hoste- lería. Sobre todo en los últimos años ha habido un cambio radical hasta el punto de que en la actualidad quizá menos de la mitad está empleado en dicho sector.

Otras profesiones frecuentes son: trabajadores en bazares (tiendas de "todo a cien"), revelado rápido de fotos ("Foto Express"), importación-exportación de variados artículos, venta ambulante de artesanía y otros objetos.

Independientemente de la actividad a la que se dediquen, trabajarán a menudo cerca de las doce horas diarias.

\section{NOMBRES}

En todas las provincias de China, en primer lugar se nombra el apellido (primer fonema). Luego sigue el nombre, que puede ser de uno o dos fonemas (p.ej., el general Chiang Kai-Shek; Chiang es el apellido, y Kai-Shek es el nombre. El mariscal Lin Piao; Lin es el apellido y Piao es el nombre). Por supuesto, como en el resto de personas de nacionalidad no hispana, el segundo apellido (correspondiente a la madre) no existe.

Algunos, sobre todo los de origen chino nacidos en España o los que llevan muchos años (décadas) viviendo aquí, han adoptado nuestras costumbres, y así pueden tener nombres cristianos (a menudo asociados a su nombre chino), que entonces anteponen al apellido. También estos pacientes pueden tener los dos apellidos.

Por tanto es fundamental que en todos nuestros registros quede apuntado con claridad lo que es el nombre y lo que es el apellido, preguntándolos por separado y una pregunta después de la otra.

Hace años, en algunas zonas de China, las mujeres casadas podían incorporar el apellido del mari do. Por ello, sobre todo en las mujeres casadas mayores de 50 años no está de más comprobar si su apellido es realmente el suyo propio o el de su cónyuge.

\section{PROBLEMAS MÉDICOS GENERALES}

En general, los inmigrantes chinos utilizan los servicios médicos o sociales y comunitarios mucho menos que los inmigrantes de otras etnias, y por supuesto que los españoles. En mi opinión, esto puede explicarse en parte porque el paciente chino es en general más sufrido y suele confiar en remedios naturales autodispensables, incluyendo fitoterapia china, masoterapia... (factores culturales). También al estar trabajando la mayor parte del día, tienen poco tiempo para acudir al médico (factores laborales). Pero quizá el mayor obstáculo sea el lingüístico. Esto es lógico si tenemos en cuenta que la mayoría de 
ellos tendría serias dificultades en hacerse entender al explicar su sintomatología, y luego estarían muy inseguros pensando si han entendido bien cómo hacer el tratamiento correctamente.

En el caso de los pacientes indocumentados, el problema todavía se acentúa más. En estos casos suelen acudir a médicos que conocen su situación (piensan que no les van a denunciar a la Policía, a diferencia de otros facultativos que no les conocen) o a servicios de urgencia de los que tengan alguna referencia. Al igual que seguramente ocurra con pacientes de otras etnias, la ignorancia absoluta acerca del funcionamiento de los servicios sanitarios y sociales unido a una dificultad lingüística para poder comunicarse, son limitaciones determinantes a la hora de acceder a dichos servicios.

Por ello, es fácil que un paciente chino, antes de acudir a la consulta con cita previa haya intentado tratamientos caseros o medicación despachada por el farmacéutico. Si el paciente reconoce haber tomado fitoterapia china, ya le advierto querido lector, que no pierda su valioso tiempo en intentar averiguar qué principios activos contiene: éstos vienen todos en chino, y en los raros casos que los nombres de las plantas vengan en latín, serán nativas y no podrá encontrar sus propiedades en cualquier vademecum occidental.

\section{CONCEPTO DE SALUD Y ENFERMEDAD}

Es difícil en pocas palabras explicar la teoría china de por qué enfermamos, pues esto nos llevaría a las bases filosóficas de la Naturaleza misma, de la que el hombre no es sino un componente más. La Naturaleza está es un continuo cambio. Esto se manifiesta básicamente en dos aspectos, el "yin" (representaría la oscuridad, la luna, lo femenino, la pasividad, lo que cede, etc.) y el "yang" (representaría la claridad, el sol, lo masculino, la actividad, lo que resiste, etc.). No son principios opuestos ni contrarios, sino complementarios e interdependientes. Tan importante es el yin como el yang, pues la ausencia total de uno anula al otro. La luz no es lo contrario de la sombra, ni lo que cede es lo contrario de lo que resiste. En una persona sana, el yin y el yang están en un continuo equilibrio dinámico. La obstrucción (déficit) o el desbordamiento (exceso) en la circulación de esa energía, produce un disbalance que resulta en la enfermedad.

\section{ALGUNOS MITOS E IDEAS MÉDICAS DE MUCHOS CHINOS}

- Goteros. Son considerados como la panacea del tratamiento de cualquier enfermedad. Muchos pacientes chinos lo primero que buscan al entrar en la consulta cuando se sienten enfermos, es "que les pongan un suero intravenoso".

-Medicamentos. Al igual que muchos otros pacientes de otras etnias (españoles incluidos), consideran que son más eficaces los de precio más elevado y/o de fabricación alemana o americana.

-Predilección por presentaciones. En general prefieren la administración por vía parenteral, salvo los pacientes más jóvenes o con acufobia.

-Medicina tradicional china/acupuntura. Habitualmente la prefieren los pacientes de mayor edad, que han vivido en China muchos años y/o pacientes jóvenes que han tenido experiencia favorable con dichos tratamientos.

- Análisis de sangre. Los pacientes chinos son muy poco partidarios de hacerse repetidos análisis de sangre, ante la creencia de que las extracciones de sangre "debilitan" la salud.

-Dentadura. La mayoría de los inmigrantes de procedencia china poseen escasa o nula cultura odontológica. Sobre todo las personas de mayor edad, consideran inevitable la caída de los dientes con la edad ${ }^{4}$. Otro de los motivos que hacen que el dentista sea poco frecuentado es la enorme diferencia de precios de los servicios odontológicos en España en comparación con los de su país de origen.

-Dieta. En general, suele ser difícil que los pacientes chinos hagan estrictamente la dieta que se les instaura. El motivo de ello probablemente sea el peso de tantos siglos de tradición, muy difícilmente modificables en una sola generación. Sobre todo en gente de edad, existe la creencia que los alimentos son "calentadores" o "enfriadores" (;de nuevo el yin y el yang!). Por ejemplo: el embarazo se le clasifica como un estado "caliente"; por ello se debe disminuir la ingesta de alimentos "calentadores": carnes rojas, grasas en general, etc. y aumentar la de alimentos "enfriadores": frutas, verduras, etc.

A los pacientes chinos ingresados, es frecuente ver cómo sus familiares y amigos les llevan los alimentos que según la medicina tradicional china, son más favorables para su enfermedad.

-Alimentación en lactantes. En la inmensa mayoría de las familias, los niños a partir de los 6 meses (máximo a los 9 meses), empezarán a tomar los más variados alimentos: huevos, carnes, pescados, frutas y verduras, etc.

-Alimentos. Los alimentos occidentales que no suelen tener mucha aceptación entre la población china son: quesos (especialmente los muy curados), jamón serrano (carne cruda) y legumbres (garbanzos y lentejas). La comida española en general la consideran muy salada y los postres demasiado dulces. El arroz se cocina en toda China (al igual que en el resto de países de influencia) mucho más hecho (pasado) de lo que se suele cocinar 
en España.

Finalmente considero interesante comentar que muy a menudo preguntan si la enfermedad es lo suficientemente grave como para tener que regresar a su país de origen para tratársela. Una gran parte de los inmigrantes chinos no acaba de fiarse del sistema sanitario de nuestro país.

\section{ALGUNOS MITOS Y POSIBLES IDEAS DE ALGUNOS MÉDICOS ESPAÑOLES}

-Pies pequeños en ancianas chinas. Puede asegurarse sin temor a error que no veremos en la actualidad patología derivada del vendaje de los pies en mujeres chinas, ni incluso entre las más ancianas. El sistema comunista afortunadamente erradicó completamente dichas prácticas.

-Alimentación "exótica". Probablemente sea más el mito que la realidad. Platos a base de sopa de aleta de tiburón, ensalada dulce de maíz y soja verde germinada, holoturias guisadas con salsa de soja, etc. podían considerarse al menos "especiales" hace algunos lustros, pero debido a la gran aceptación de la cocina china por parte de nuestro país, se ha desmitificado bastante. Aunque hay numerosos ingredientes no familiares al gusto español, platos como los sesos de mono, y aderezos con cuerno de rinoceronte o huesos de tigre son más fantasías que realidades.

-Omnipresente medicina tradicional china = acupuntura. Hay dos errores en esta afirmación. Primer error: la acupuntura es sólo una parte de la medicina tradicional china. Segundo error: muchos pacientes (sobre todo los más jóvenes), nunca se han llegado a tratar con acupuntura, aunque en general, los que han venido a España con más de cuarenta años de edad, es muy difícil que no hayan sido tratados en alguna ocasión mediante alguna de las técnicas de la medicina tradicional china (fitoterapia, acupuntura, digitopuntura, moxibustión, etc.).

- Sumisión de la mujer china. Es inútil negar que secularmente la mujer china ha sido considerada como la sumisión personificada. Esto probablemente se debiera a la milenaria doctrina confucionista, que situaba al hombre como el cabeza de familia y que debía actuar como tal para que se siguiera el orden natural del universo. Esta misma idea era la que se desprende de la lectura de las decenas de novelas que nos dejó en legado la premio nobel de literatura, la norteamericana Pearl S. Buck. Pero la "revolución cultural" de Mao primero, y la occidentalización de la vida en China posteriormente, cambiaron el panorama. La igualdad del hombre y de la mujer se hizo patente en prácticamente todos los aspectos de la vida en la nueva China, pasando lenta pero progresivamente a la historia la secular "sumisión femenina". PATOLOGÍAS MÁS PREVALENTES

\section{En pediatría}

\section{Intolerancia a lactosa}

Es debida a una deficiencia de lactasa (lactasa florizin hidrolasa), enzima que hidroliza el disacárido lactosa en glucosa y galactosa. Los niveles de dicha enzima son elevados en el nacimiento, decayendo progresivamente con el tiempo. Por ello, la clínica suele empezar cuando el niño tiene varios años de edad. Al poco tiempo de ingerir leche o derivados lácteos, aparecen molestias abdominales inespecíficas, flatulencia y diarrea. El yoghurt puede ser algo mejor tolerado ${ }^{1}$.

\section{Síndromes talasémicos}

Muy frecuentes en China y todo el sudeste asiáti$\mathrm{co}^{5}$. Hay muchas variedades distintas, clasificables por el tipo de cadena de hemoglobina afecta en:

1. Alfa-talasemia: especialmente frecuente en la población de origen taiwanés (autóctono): $4 \%$, frente al $0,4 \%$ de la población de origen chino continental ${ }^{6}$. En estado heterocigoto puede ser asintomático. En estado homocigoto, si la hemoglobina predominante es la Barts (el oxígeno no llega a los tejidos), el cuadro clínico es el de una hidropesia fetal, cuadro incompatible con la vida. El niño puede morir intraútero o a las pocas horas del nacimiento. Es fundamental ante una paciente sospechosa por los datos antedichos, un diagnóstico prenatal y consejo genético ${ }^{7}$. Otra forma especial de alfa-talasemia es la enfermedad por hemoglobina $\mathrm{H}$, en la que están alterados tres de los cuatro genes que codifican alfaglobinas, situados en el cromosoma $16^{8}$. Durante el primer año de vida aparecen signos similares aunque menos intensos a los de una anemia de Cooley.

2. Beta-talasemia: la más frecuente es la talasemia minor, heterocigota, que va asociada con una anemia leve (Hb: 2-3 g/dl por debajo de lo normal), con microcitosis, hipocromia y volúmenes muy bajos (<69 micras cúbicas).

\section{Déficit de glucosa 6 fosfato dehidrogenasa}

Sobre todo frecuentes en el sur de China: Cantón, Hong Kong y Macao (cantonés-parlantes). Hay descritas diversas variantes orientales de déficit de G6PD, aunque clínicamente son todas superponibles a la variante mediterránea ${ }^{1}$.

En recién nacidos puede producirse un cuadro clínico de ictericia hemolítica que puede requerir 
tratamiento con exanguinotransfusión.

El cuadro clínico más habitual es el de una hemólisis aguda intravascular pocos días después de ingerir alguna medicación (sobre todo sulfamidas, analgésicos, etc.), infección aguda, ingesta de habas, etc. En sangre son característicos los cuerpos de Heinz.

\section{Mancha mongólica (melanocitosis dermal congénita)}

No es propiamente una enfermedad, pero su conocimiento es necesario para no confundirlo con otras patologías. Presente en el $86 \%$ de los recién nacidos de origen chino ${ }^{9}$ y en menos del $10 \%$ de los de raza blanca. Consiste en máculas azuladasnegras, en diferentes tonalidades, situadas casi siempre en la región lumbar y/o sacra, de muy distintos tamaños. Pueden no desaparecer totalmente en el $3 \%$ de los casos, persistiendo entonces restos maculares en adultos.

Una variante de la anterior, y con idénticas características clínicas es el escroto hiperpigmentado, presente en el $31 \%$ de los neonatos varones chinos?

\section{En medicina general}

\section{Intolerancia a lactosa}

Por déficit de lactasa. Cerca del $80 \%$ de los chinos tienen cierto grado de intolerancia a lactosa. La clínica es similar a la descrita más arriba en la edad pediátrica.

\section{Hepatitis B}

La prevalencia de marcadores del virus $\mathrm{HB}$ es cercana al $80 \%$ y la de portadores del $15 \%$. En Hong-Kong la mitad de la población ha tenido contacto con el $\mathrm{VHB}^{10}$. Hoy se acepta que la altísima prevalencia de portadores de VHB en la población china se debe a la transmisión materno-infantil durante el parto ${ }^{11}$.

El manejo de dichos pacientes, el de sus familiares y contactos íntimos, no difiere en cuanto a la prevención y el tratamiento, de los habitualmente empleados en nuestro medio.

\section{Hepatoma (hepatocarcinoma)}

Elevadísima incidencia de hepatoma, asociado a hepatitis crónica B y a veces familiar en chinos nacidos y criados en China ${ }^{12}$. Existe un importante componente ambiental, pues los hijos de éstos, na- cidos y criados en Estados Unidos ${ }^{13}$ o Singapur ${ }^{14}$ tienen menor incidencia que sus padres, aunque mayor que la de los americanos ${ }^{13}$. Los varones predominan 4-5 a 1 con un pico máximo a los 70 años $^{14}$.

\section{Carcinoma de nasofaringe}

El carcinoma de células escamosas es uno de los tumores más frecuentes en pacientes de origen chino, sobre todo en la zona sur de China y del sureste asiático. El virus de Epstein-Barr está implicado en su génesis. La media de edad de su presentación son 52 años, con un predominio de varones en la proporción de 2,5:1. En comparación con los norteamericanos de raza blanca, los chinos nacidos en China tienen una incidencia ¡ 117 ! veces superior, mientras que en los chinos nacidos en Estados Unidos, dicha incidencia es de 7,3 veces mayor ${ }^{15}$.

El primer síntoma suele ser la obstrucción nasal o de la trompa de Eustaquio, que puede producir un derrame en el oído medio. Otros síntomas son: rinorrea sanguinopurulenta, epistaxis intensa, parálisis de pares craneales, etc. Posteriormente, puede palparse una masa cervical.

\section{Carcinoma esofágico}

El más frecuente es el carcinoma de células es camosas. Posiblemente asociado a déficit de vitaminas A, B y C, de minerales como $\mathrm{Zn}$ y $\mathrm{Mb}$ y de nitrosaminas.

Debuta como disfagia (preferentemente a alimentos sólidos) y son más frecuentes en varones y en ancianos ${ }^{16}$.

\section{Carcinoma gástrico}

Es principalmente el adenocarcinoma gástrico el que tiene una mayor incidencia en China y Japón que en otros países. Su diagnóstico clínico precoz es difícil. Posiblemente esté indicada la gastroscopia en pacientes de etnia china, mayores de 55 años y que refieran sensación de plenitud y/o pirosis. De hecho, en Japón la endoscopia se utiliza para la detección selectiva sistemática.

No obstante el pronóstico global es menos malo que en otras etnias, al parecer porque la diseminación cancerosa sucede más por vía linfática ${ }^{17}$, siendo tres veces menor la proporción de metástasis hepáticas en pacientes de etnia china afectos de adenocarcinoma gástrico en relación a otras etnias ${ }^{18}$.

\section{Colelitiasis}

Altísima prevalencia en Taiwan $(53,5 \%)$ en 
comparación con las de Hong Kong $(3,1 \%)$ y Singapur $(1,7 \%)$. Siendo la población de las tres localizaciones antes mencionadas mayoritariamente de descendencia china, es razonable pensar que deben influir más las causas medioambientales que étnicas para explicar estas diferencias ${ }^{19}$.

\section{PATOLOGÍAS MENOS PREVALENTES}

Clínicamente tienen mucha menor relevancia, pero puede ser útil saber que en general, la incidencia de las siguientes enfermedades es menor que en la raza blanca: obesidad ${ }^{20}$, coxartrosis ${ }^{21}$, leucoplasias en cavidad oral ${ }^{22}$, arteritis de células gigantes ${ }^{23}$, esclerosis múltiple ${ }^{24}$, enfermedad de Hodgkin ${ }^{25}$, linfomas foliculares ${ }^{25,26}$, enfermedad de Paget ósea ${ }^{27}$, psoriasis, melanoma (dentro de su baja frecuencia, sus localizaciones más frecuentes son en palmas, plantas, lechos ungueales y mucosas; a diferencia que en la raza blanca, donde se distribuyen por toda la superficie corporal $)^{28}$ y dermatitis herpetifor$\mathrm{me}^{29}$.

\section{MISCELÁNEA. OTRAS PATOLOGÍAS}

-Síndrome del Restaurante Chino. Este síndrome, descrito por vez primera por $\mathrm{Kwok}^{30}$, consiste en la aparición unos 15 a 20 minutos después del inicio de ingesta de comida china preparada con glutamato monosódico de: acorchamiento cervical posterior con irradiación a ambos brazos y espalda, debilidad general y palpitaciones. La duración del cuadro es de aproximadamente 2 horas, sin dejar resaca. Estudios epidemiológicos especialmente diseñados para conocer su prevalencia y relación con el glutamato monosódico, cuestionan seriamente su existencia ${ }^{31,32}$.

La realidad es que no existen datos de prevalencia de este síndrome. Aunque ha sido y es mencionado en casi todos los textos, la modesta opinión del autor de este artículo es que en nuestro medio, dicha prevalencia debe ser bajísima. En mis 19 años de ejercicio profesional no he conocido personalmente ni he tenido referencias de nadie (ni chino, ni español ni de otra nacionalidad) que tomando glutamato monosódico y/o comida china, haya padecido la sintomatología arriba descrita.
-Metabolización de bebidas alcohólicas. El alcohol es metabolizado en el organismo principalmente por las isoenzimas alcohol deshidrogenasas (ADHs) y citocromo P450 2E 1 (CYP2E1). Convierten el etanol en acetaldehído, el cual es oxidado en acetato por la aldehido deshidrogenasa ALDH2. Cuando la actividad de esta enzima disminuye, se acumula acetaldehído en el hígado y en la circulación. Esto produce como consecuencia síntomas de flushing, taquicardia e incluso colapso circulatorio. Aproximadamente la mitad de la población china es deficiente en aldehido deshidrogenasa. Ello es debido a la herencia del alelo $\mathrm{ALDH} 2 * 2$, que codifica una enzima inactiva.

- Acetilación. Una serie de fármacos (isoniacida, hidralacina, procainamida, etc.) son metabolizados mediante acetilación de un grupo hidracino o amino. Esta reacción está catalizada por la enzima hepática $\mathrm{N}$-acetil transferasa, que transfiere un gru po acetil del acetil coenzima A al fármaco. La velocidad de la acetilación está genéticamente contro lada y la acetilación lenta se hereda de forma autosómica recesiva. Entre la población de raza china abundan los acetiladores lentos.

\section{CONCLUSIONES}

Debido al creciente número de personas inmigrantes en nuestro país, sería deseable que todo médico de familia tuviera una formación actualizada de las patologías más prevalentes en las distintas etnias.

Aunque los pacientes de etnia china no son frecuentes en nuestra consulta diaria, sí pueden ser con los que más dificultades tengamos a la hora de comunicarnos. El hecho de conocer mejor sus costumbres y patologías más frecuentes, probablemente nos será útil en el abordaje clínico de dichos pacientes.

También sería deseable poder encontrar mediadores entre la comunidad china en España y el sistema socio sanitario español, para que los inmigrantes chinos puedan tener igualdad de oportunidades en el acceso a dichos sistemas que el resto de inmigrantes y españoles. 
SÍ $=$ 是

NO $=$ 不是

DÓNDE $=$ 什么地方 $?$ 哪里 $?$

IRRADIA = 扩展、扩散

DESDE CUÁNDO = 从什么时候开始?

CUÁNTO = 多少?

NORMAL = 正常、一般

MUCHO $=$ 很、非常

POCO = 少

INTERNO $=$ 内科、内部

EXTERNO $=$ 外科、外面

IZQUIERDO $=$ 左

DERECHO $=$ 右

SUPERIOR $=$ 上面、上边

INFERIOR = 下面、下边

ROJO = 红

BLANCO $=$ 白

VERDE $=$ 绿

AMARILLO $=$ 黄

SECO $=$ 干

HÚMEDO $=$ 湿

BUENO $=$ 好

MALO $=$ 坏

MEJORA = 病情进步、转好; 改善

EMPEORA = 病情转坏; 恶化

SE CONTROLA = 控制

DE PIE = 站

SENTADO $=$ 坐

TUMBADO $=$ 卧、躺着

MÉDICO = 医生、医师、大夫

ENFERMERA $=$ 护士

HOSPITAL $=$ 医院

CENTRO DE SALUD = 卫生所、医疗中，

ESPECIALISTA = 专科医师、专家

DENTISTA $=$ 牙医

PEDIATRA $=$ 小儿科医师

GINECÓLOGO $=$ 妇科医师

CIRUJANO $=$ 外科医师
SALUD $=$ 卫生

ENFERMEDAD $=$ 疾病

DOLOR $=$ 疼痛

$\mathrm{PICOR}=$ 痒

FIEBRE $=$ 发烧

TERMÓMETRO $=$ 温度计

INFLAMACIÓN = 发炎、红肿

INFECCIÓN = 感染、传染

MICROBIO = 细菌

PIOJOS = 虫子

INTOXICACIÓN $=$ 中毒

HINCHAZÓN = 肿胀、肿起来

NÁUSEAS = 恶心、想吐

VÓMITO $=$ 呕吐、吐

DIARREA $=$ 泻肚、拉肚子

ESTREÑIMIENTO $=$ 便秘

TOS = 咳濑

ESPUTO $=$ 痰、唾沫

ESTORNUDO $=$ 打喷德

DISNEA = 呼吸困难

SANGRE $=$ 血、血液

ORINA = 尿、小便

HECES $=$ 粪便、大便

PUS $=$ 服

SECRECIÓN = 分泌物

SÓLIDO $=$ 硬

LÍQUIDO $=$ 液体

$\mathrm{GAS}=$ 肠胃气

ÚLCERA $=$ 溃疡

MUERTE $=$ 死亡

PADRE = 父亲、爸爸

MADRE = 母亲、妈妈

$\mathrm{HIJO}=$ 儿子

$\mathrm{HIJA}=$ 女儿

VISTA $=$ 视力

OÍDO = 听力

OLFATO $=$ 嗅觉

ALERGIA $=$ 过敏

OPERACIÓN = 开刀、手术

VACUNA $=$ 疫苗、预防针 
MEDICACIÓN $=$ 药、药品

PASTILLA = 药片

JARABE $=$ 糖浆、甜药水

SOBRES = 包 (药粉)

SUPOSITORIOS $=$ 坐药 $($ 插入肘门的药 $)$

INYECCIÓN $=$ 注射、打针

EMBARAZO $=$ 怀芓

$\mathrm{ABORTO}=$ 流产、葄胎

$\mathrm{TABACO}=$ 香烟

ALCOHOL $=$ 酒精、酒 $($ 含酒精 $)$

DROGA $($ DURA $)=$ 毒品 $($ 硬性 $)$

CORAZÓN $=$ 心脏

PULMÓN = 肺

BRONQUIO $=$ 支气管

FARINGE $=$ 咽

LARINGE $=$ 喉

ESÓFAGO $=$ 食道

ESTÓMAGO = 胃

INTESTINO DELGADO $=$ 小肠

APÉNDICE $=$ 盲肠

INTESTINO GRUESO $=$ 大肠

RECTO $=$ 直肠

$\mathrm{ANO}=$ 肛门

HÍGADO $=$ 肝

VESÍCULA BILIAR $=$ 胆囊

PÁNCREAS $=$ 胰腺

RIÑÓN = 肾脏

VEJIGA URINARIA $=$ 膀胱

PRÓSTATA $=$ 前列腺

TESTÍCULO $=$ 睪丸

ÚTERO = 子宫

OVARIO $=$ 卵巢

VAGINA $=$ 阴道
ARTERIA $=$ 动脉

VENA $=$ 血管

GANGLIO LINFÁTICO $=$ 淋巴结

MÚSCULO $=$ 肌肉

TENDÓN $=$ 腱

$\mathrm{PIEL}=$ 皮肤

HEMATÍES $=$ 红血球

LEUCOCITOS $=$ 白血球

GLUCOSA = 葡萄糖、醣

COLESTEROL $=$ 胆固醇

ANEMIA $=$ 贫血

ASMA $=$ 气喘、哮喘

ALERGIA PRIMAVERAL $=$ 春季过敏

TUBERCULOSIS $=$ 肺疷

SIDA $=$ 爱滋病

HEPATITIS $=$ 肝炎

NEUMONÍA $=$ 肺炎

INFECCIÓN URINARIA $=$ 尿道炎

HIPERTENSIÓN ARTERIAL $=$ 高血压 HIPOTENSIÓN ARTERIAL $=$ 低血压

DIABETES MELLITUS $=$ 糖尿病

VARICES $=$ 静脉曲张

HEMORROIDES $=$ 庤疮

COLELITIASIS $=$ 胆石病

VENÉREO = 性病、花柳病

CÁNCER = 癌、恶性肿瘤
Área de Servicios Sociales Mediadores.

Ayuntamiento de Madrid. Telf: 91.588.50.96.

Comrade. Telf: 91.446 .29 .51
Embajada de la República Popular China en Madrid. Telf: 91.519.42.42.

Oficina Económica y Cultural de Taipei en Madrid. Telf: 91.571.84.26.
Asociación Amigos de China. Telf: 91.361.45.73.

Anexo 2 Teléfonos útiles 


\section{Bibliografía}

1. Black J. Chinese and Vietnamese families. BMJ 1985; 290: 1063-5.

2. Abbott MW, Wong S, Williams M, Au MK, Young W. Recent Chinese migrants' health, adjustment to life in New Zealand and primary health care utilization. Disabil Rehabil 2000; 22: 43-56.

3. Ly Pen D. Tres mitos del Extremo Oriente: Confucio, Lao-Tzé, Buda. 1976; (manuscrito sin editar).

4. Kwan SY, Williams SA. Dental beliefs, knowledge and behaviour of Chinese people in the United Kingdom. Community Dent Health 1999; 16: 33-9.

5. Li AM, Cheng MY. Anaemia and thalassaemia in healthy adolescents from southern Chinese families. J Paediatr Child Health 1990; 26: 339-42.

6. Lin CK, Lee SH, Wang CC, Jiang ML, Hsu HC. Alphathalassemic traits are common in the Taiwanese population: usefulness of a modified hemoglobin $\mathrm{H}$ preparation for prevalence studies. J Lab Clin Med 1991;118: 599-603.

7. Yong KN, Wadsworth D, Langlois S, Yong SL, Wilson RD. Thalassemia carrier screening and prenatal diagnosis among the British Columbia (Canada) population of Chinese descent. Clin Genet 1999; 55: 20-5.

8. Chen FE, Ooi C, Ha SY, Cheung BM, Todd D, Liang $\mathrm{R}$, et al. Genetic and clinical features of hemoglobin $\mathrm{H}$ disease in Chinese patients. N Engl J Med 2000; 343: 544-50.

9. Tsai FJ, Tsai $\mathrm{CH}$. Birthmarks and congenital skin lesions in Chinese newborns. J Formos Med Assoc 1993; 92: 838-41.

10. Tang KY. Hepatitis B, 1997 and the Chinese community, an appraisal of their relationships. J Public Health Med 1997; 19: 200-2.

11. Lok AS. Natural history and control of perinatally acquired hepatitis B virus infection. Dig Dis 1992; 10: 46-52.

12. Shen FM, Lee MK, Gong HM, Cai XQ, King MC. Complex segregation analysis of primary hepatocellular carcinoma in Chinese families: interaction of inherited susceptibility and hepatitis B viral infection. Am J Hum Genet 1991; 49: 88-93.

13. Rosemblatt KA, Weiss NS, Schwartz SM. Liver cancer in Asian migrants to the United States and their descendants. Cancer Causes Control 1996; 7: 345-50.

14. Chia KS, Lee HP, Lee J. Incidence of primary liver cancer in Singapore, 1968-1982. Ann Acad Med Singapore 1989; 18: 313-6.

15. Dickson RI. Nasopharyngeal carcinoma: an evaluation of 209 patients. Laryngoscope 1981; 91: 333-54.

16. Cheng KK, Day NE, Duffy SW, Lam TH, Fok M, Wong $J$. Pickled vegetables in the aetiology of oesophageal cancer in Hong Kong Chinese. Lancet 1992; 339: $1314-8$

17. Theuer CP. Asian gastric cancer patients at a southern California comprehensive cancer center are diag- nosed with less advanced disease and have superior stage-stratified survival. Am Surg 2000; 66: 821-6.

18. Steele RJ, Chung SC, Li AK, Crofts TJ. Hepatic metastases in Hong Kong Chinese: evidence for an East-West difference in gastric cancer. Ann R Coll Surg Engl 1987; 69: 61-3.

19. Nakayama F, Soloway RD, Nakama T, Miyazaki K, Ichimiya $\mathrm{H}$, Sheen PC, et al. Hepatolithiasis in East Asia. Retrospective study. Dig Dis Sci 1986; 31: 21-6.

20. WHO. Programme of Nutrition, Family and Reproductive Health. Obesity. Preventing and managing the global epidemic. Report of a WHO consultation on obesity. Geneva, 3-5 June, 1997; Geneva: WHO, 1998.

21. Das De S, Bose K, Balasubramaniam P, Goh JC, Teng B. Surface morphology of Asian cadaveric hips. J Bone Joint Surg (Br) 1985; 67: 225-8.

22. Zain RB, Ikedad N, Razak IA, Axell T, Majid ZA, Gupta $P C$, et al. A national epidemiological survey of oral mucosal lesions in Malasya. Community Dent Oral Epidemiol 1997; 25: 377-83.

23. Wing $Y K$, Kay RL, Lai FM. Giant cell arteritis in two Chinese patients. Aust N Z J Med 1991; 21: 751-2.

24. Yu YL, Woo E, Hawkins BR, Ho HC, Huang CY. Multiple sclerosis amongst Chinese in Hong Kong. Brain 1989; 112: 1445-67.

25. Liang R, Choi P, Todd D, Chan TK, Choy D, Ho F. Hodgkin's disease in Hong Kong Chinese. Hematol Oncol 1989; 7: 395-403.

26. Ho FC, Todd D, Loke SL, Ng RP, Khoo RK. Clinicopathological features of malignant lymphomas in 294 Hong Kong Chinese patients, retrospective study covering an eight year period. Int J Cancer. 1984; 34: 143-8.

27. Sirikulchayanonta $V$, Naovaratanophas $P$, Jesdapatarakul $S$. Paget's disease of bone, clinicopathology study of the first case report in Thailand. J Med Assoc Thai 1992; 75 (Suppl 1): 136-9.

28. Seiji M. Malignant melanoma of the palmar-plantarsubungueal-mucosal type: clinical and histopathological features, in Pigment Cell, vol 5, edited by SN Klaus. Basel, Karger, 1979, pp 95.

29. Ratnam KV. Ig A dermatosis in an adult Chinese population. A 10 year study of linear $\lg A$ and dermatitis herpetiformis in Singapore. Int J Dermatol 1998; 27: 21-4.

30. Kwok RHM. Chinese-restaurant syndrome. N Engl J Med 1968; 278: 796.

31. Kerr GR, Wu-Lee M, El-Lozy M, McGandy R, Stare FJ. Prevalence of the "Chinese restaurant syndrome". J Am Diet Assoc 1979; 75: 29-33.

32. Wilkin JK. Does monosodium glutamate cause flushing (or merely "glutamania")? J Am Acad Dermatol 1986; 15: 225-30. 